\title{
Positive geothermal anomalies in oceanic crust of Cretaceous age offshore Kamchatka
}

\author{
G. Delisle \\ Bundesanstalt für Geowissenschaften und Rohstoffe (BGR), Stilleweg 2, 30655 Hannover, Germany \\ Received: 6 April 2011 - Published in Solid Earth Discuss.: 12 May 2011 \\ Revised: 4 August 2011 - Accepted: 10 August 2011 - Published: 26 September 2011
}

\begin{abstract}
Heat flow measurements were carried out in 2009 offshore Kamchatka during the German-Russian jointexpedition KALMAR. An area with elevated heat flow in oceanic crust of Cretaceous age - detected $\sim 30 \mathrm{yr}$ ago in the course of several Russian heat flow surveys - was revisited. One previous interpretation postulated anomalous lithospheric conditions or a connection between a postulated mantle plume at great depth $(>200 \mathrm{~km})$ as the source for the observed high heat flow. However, the positive heat flow anomaly - as our bathymetric data show - is closely associated with the fragmentation of the western flank of the Meiji Seamount into a horst and graben structure initiated during descent of the oceanic crust into the subduction zone offshore Kamchatka. This paper offers an alternative interpretation, which connects high heat flow primarily with natural convection of fluids in the fragmented rock mass and, as a potential additional factor, high rates of erosion, for which evidence is available from our collected bathymetric image. Given high erosion rates, warm rock material at depth rises to nearer the sea floor, where it cools and causes temporary elevated heat flow.
\end{abstract}

\section{Introduction}

Marine-geologic probing and heat flow measurements were carried out offshore Kamchatka during cruise 201 Leg 2 with the German R/V SONNE as part of the GermanRussian KALMAR-project (Kurile-Kamchatka and Aleutian marginal sea-island arc systems). One of the objectives of KALMAR focuses on the geodynamic and volcanologicalmagmatic development of the Kurile-Kamchatka island arc system and the Aleutian Islands Triple-Junction. Restrictions

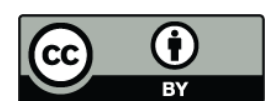

Correspondence to: G. Delisle (georg.delisle@bgr.de) outlined by the research license issued by Russian authorities reduced the permissible points for heat flow measurements to two areas south of the Kamchatka-Aleutian-Islands-Triple Junction (red boxes in Fig. 1a). These areas are characterized by oceanic crust on the verge of being subducted under the Kamchatka Peninsula. On top of the oceanic crust rest seamounts of the Emperor Seamount Chain, of which the Meiji Seamount forms the front complex, which has started to descend toward the $6 \mathrm{~km}$ deep subduction trench. The presence of a large positive heat flow anomaly along the western flank of the Meiji Seamount is discussed in the literature (see below). The presence of high heat flow in crust of Cretaceous age (Creager et al., 1973) is in itself a surprise. The work presented here concentrates on this aspect.

\section{Previous work}

First heat flow measurements in the area by (see for details Smirnov and Sugrobov, 1979, 1980, 1982; Smirnov et al., 1991, Tuezov et al., 1991; Sugrobov and Yanovsky, 1993) indicated an area of high heat flow to the north of the Aleutian trench in the Komandorsky Basin and significantly lower heat flow to the south, with the exception of a positive heat flow anomaly to the northwest of the Meiji Seamount, trending from about $53^{\circ} \mathrm{N} ; 164^{\circ} \mathrm{E}$ toward $55^{\circ} 30^{\prime} \mathrm{N}, 164^{\circ} 30^{\prime} \mathrm{E}$ (Fig. 1b). Various workers suggested that the high heat flow areas result from atypical thermal conditions throughout the descending oceanic plate. Gorbatov et al. (1997) studied seismicity and structure of the Kamchatka subduction zone. One of their objectives was to search for a "relation between the changes in the maximum depth of seismicity and the thermal parameter of the subducted plate at the Kamchatka subduction zone (KSZ)". They noted a systematic shallower dip angle of the "upper surface of the subducted slab" (Fig. 11 therein) north of about $54^{\circ} 20^{\prime} \mathrm{N}$ along and to the west of the subduction trench and related this observation to a reduced

Published by Copernicus Publications on behalf of the European Geosciences Union. 

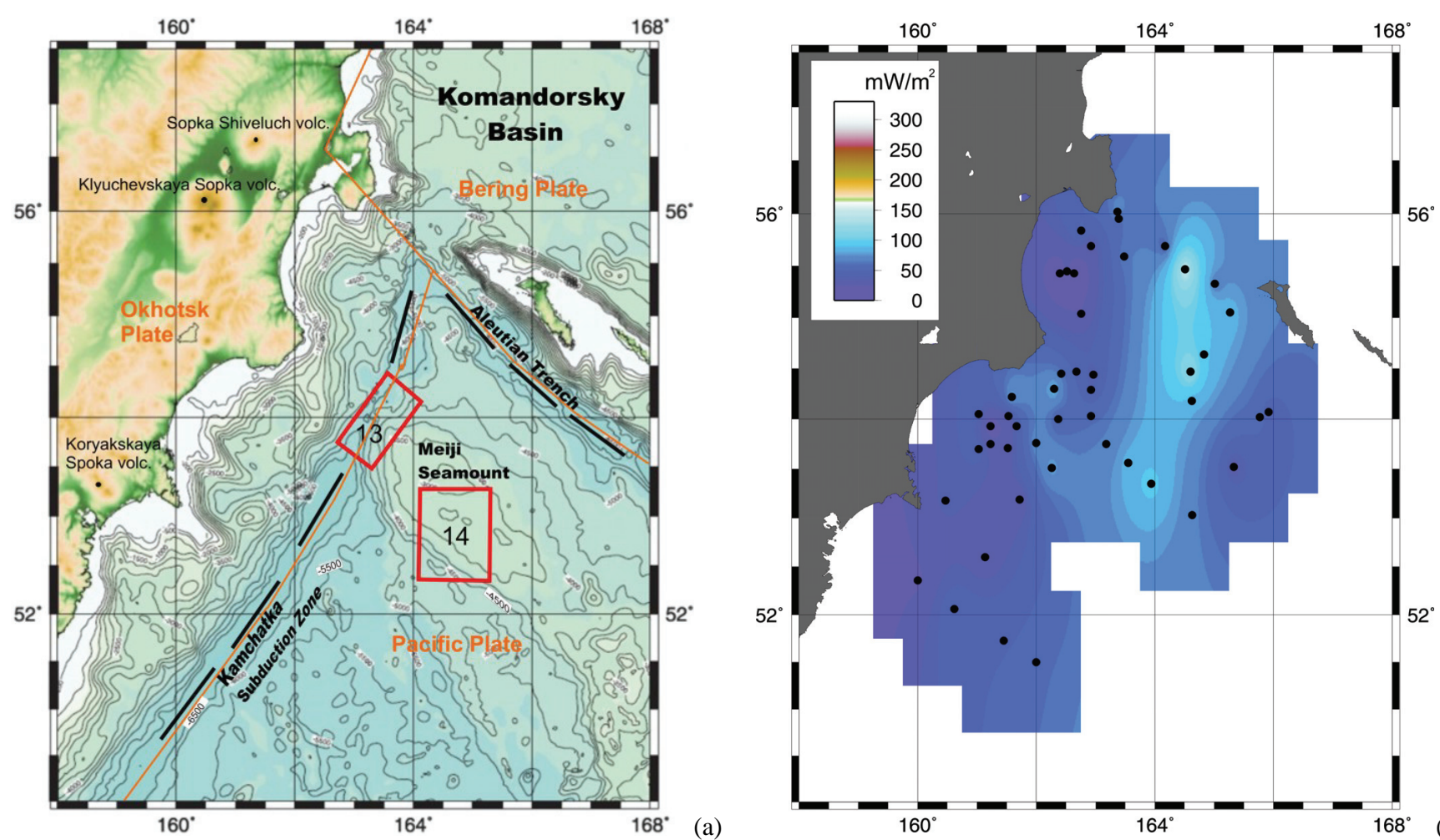

Fig. 1. (a) Bathymetric map of the southern portion of the research area investigated by a German-Russian team during cruise SO201-2 with R/V Sonne. Research permits for heat flow measurements were granted only for areas 13 and 14. Map was processed with GMT, Mercator projection (WGS 84); bathymetry by GEBCO. (b) Isoline plot of previously measured heat flow values measured by Russian workers in the late 70ies to early 80ies of last century (data taken from Smirnov et al., 1991).

thermal thickness of the subducted plate and therefore thinner lithosphere north of the Meiji Seamount. In a followup paper, Gorbatov et al. (2001) proposed the existence of a mantle plume ocean wards of the Kamchatka-Aleutian trench junction based on a topographic evaluation of P-wave travel times in the area. The plume volume characterized by anomalously low P-wave velocities $(\sim-2 \%)$ extends in almost vertical fashion, extending from 900 to $200 \mathrm{~km}$ depth and features a subsidiary anomaly that extends subhorizontally to the NW in fair agreement with the direction of the movement of the oceanic plate. The authors further speculated that the positive heat flow anomalies to the northwest of the Meiji Seamount may be somehow connected with the proposed plume. Levin et al. (2002) presented images of the seismic structure beneath the Kamchatka-Aleutian junction and proposed the occurrence of two episodes of catastrophic slab loss within the last $10 \mathrm{Myr}$ beneath Kamchatka. Upward flow of asthenospheric material in response to slab loss is proposed, but no connection between this process and anomalous heat flow on the ocean floor was drawn. To the contrary, their transect $C C^{\prime}$ (Figs. 2 and 3 therein) shows slightly enhanced shear wave velocities down to a depth of about $75 \mathrm{~km}$ within the down going oceanic plate of the Emperor Seamount chain, which would imply rather cool thermal conditions. Yogodzinski et al. (2001) discussed the possibility of mantle flow around the northern edge of the subducting Pacific plate and melting at the plate edges of the down going oceanic lithosphere. The thermal influence of the hot Komandorsky basin and the Bering Transform zone on the under Kamchatka descending Pacific plate and other potential processes to produce the observed anomalous heat flow distribution were discussed by Davaille and Lees (2004). They noted the limited thermal influence of the hot Komandorsky basin on the descending plate and suggested lithospheric thinning as the more probable cause of the observed high heat flow near the Meiji seamount.

\section{New marine heat flow measurements}

Previous marine heat flow measurements between the Meiji seamount and the coastline of Kamchatka had identified several areas of high heat flow $\left(\sim 100 \mathrm{~m} \mathrm{Wm}^{-2}\right)$ surrounded by terrain characterized by low heat flow $\left(\sim 50 \mathrm{~m} \mathrm{Wm}^{-2}\right)$. High heat flow near the Kamchatka coastline might well be associated with the volcanism on land. High heat flow away from the coastline, measured on top of old oceanic crust that should have lost, in essence by now, its excess heat obtained during emplacement, is surprising and calls for some type of 
Table 1. Summary of the measured heat flow values during KALMAR 20. Values in brackets indicate order of magnitude of site-specific terrain correction (see also Sect. 5).

\begin{tabular}{|c|c|c|c|c|c|c|c|c|c|}
\hline Station & Lat. & Long. & $\begin{array}{l}\text { Water } \\
\text { depth } \\
(\mathrm{m})\end{array}$ & $\begin{array}{c}\text { Thermal } \\
\text { conductivity } \\
\left(\mathrm{W} \mathrm{mK} \mathrm{m}^{-1}\right)\end{array}$ & $\begin{array}{l}\text { Standard } \\
\text { deviation } \\
\left(\mathrm{W} \mathrm{mK} \mathrm{m}^{-1}\right)\end{array}$ & $\begin{array}{c}T \text {-gradient } \\
\left(\mathrm{K} \mathrm{m}^{-1}\right)\end{array}$ & $\begin{array}{l}\text { Standard } \\
\text { deviation } \\
\left(\mathrm{K} \mathrm{m}^{-1}\right)\end{array}$ & $\begin{array}{l}\text { Heat flow } \\
\left(\mathrm{mW} \mathrm{m}^{-2}\right)\end{array}$ & Area \\
\hline HF17 & $54^{\circ} \mathrm{N}$ & $163^{\circ} 20^{\prime} \mathrm{E}$ & 5285 & 0.96 & 0.08 & 0.112 & $0.079^{*}$ & $107.5(-15)$ & 13 \\
\hline $\mathrm{HF} 25$ & $54^{\circ} 5^{\prime} \mathrm{N}$ & $163^{\circ} 37^{\prime} \mathrm{E}$ & 4994 & 0.89 & 0.13 & 0.112 & 0.016 & $99.7(+1)$ & 13 \\
\hline $\mathrm{HF} 27$ & $54^{\circ} 9.4^{\prime} \mathrm{N}$ & $163^{\circ} 36.6^{\prime} \mathrm{E}$ & 5471 & 1.39 & 0.28 & 0.194 & 0.02 & $269.7(-13)$ & 13 \\
\hline HF29 & $53^{\circ} 52^{\prime} \mathrm{N}$ & $163^{\circ} 48^{\prime} \mathrm{E}$ & 3891 & 1.05 & 0.23 & 0.267 & 0.035 & 280.3 & 13 \\
\hline HF34 & $53^{\circ} 15.45^{\prime} \mathrm{N}$ & $164^{\circ} 17.5^{\prime} \mathrm{E}$ & 2996 & 0.85 & 0.04 & 0.104 & $0.061^{* *}$ & 88.4 & 14 \\
\hline HF36 & $53^{\circ} 7.16^{\prime} \mathrm{N}$ & $164^{\circ} 34.4^{\prime} \mathrm{E}$ & 3223 & 0.86 & 0.04 & 0.050 & 0.008 & 43.0 & 14 \\
\hline HF38 & $53^{\circ} 11.3^{\prime} \mathrm{N}$ & $165^{\circ} 5.48^{\prime} \mathrm{E}$ & 3205 & 0.81 & 0.055 & 0.063 & 0.025 & 51.0 & 14 \\
\hline
\end{tabular}

* Removing one obvious outlier, standard deviation reduces to 0.013 .

** Removing one obvious outlier, standard deviation reduces to 0.018 .
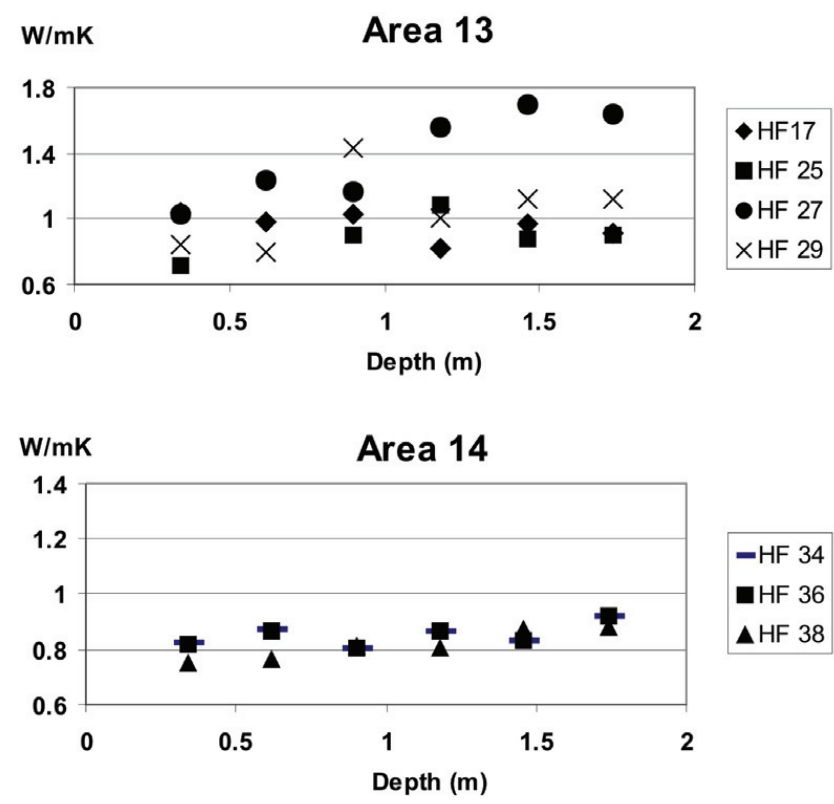

Fig. 2. In-situ thermal conductivities of the marine top sediments were measured by heated line source method at all heat flow stations. With exception of HF17, thermal conductivity values increase with depth.

"modern" heat source. To further clarify this point, we have carried out additional heat flow measurements offshore Kamchatka (Fig. 1a) during the KALMAR-expedition in 2009 (Leg 2) in the areas 13 and 14 (these two areas were open for heat flow measurements according to the issued Russian research permit) along a northwest-southeast transect from the eastern flank of the Kamchatka trench to the Meiji seamount (coordinates of points of measurement are given in Table 1).

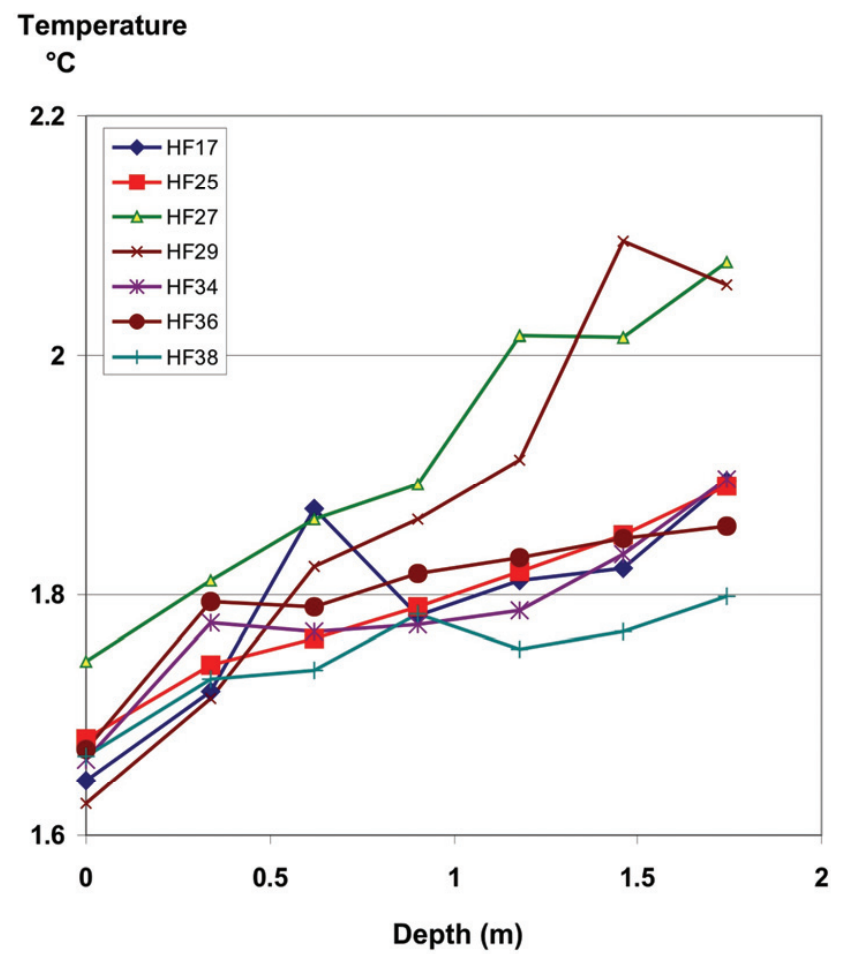

Fig. 3. Summary of all temperature gradients measured during cruise SO201-2. The majority of stations show a well defined linear temperature increase with depth.

\section{Methods}

We have deployed a "hard ground" heat flow probe, which is particularly suited for moderately compacted seafloor sediments. Technical details of this instrument can be found in Delisle and Zeibig (2007). The principal concept of this instrument is to provide a capability for the forced penetration of compacted sediment by a thin rod under the load of an applied heavy weight. As is the case with the conventional heat 
flow probes, this instrument measures the in-situ thermal gradient and the in-situ thermal conductivity $(\lambda)$. $\lambda$-values are determined by evaluating the logarithmic increase of temperatures at the contact between penetrated sediment and the measuring rod, observable several minutes after initiation of heating of the rod under a constant thermal load.

We collect indirect evidence for the hardness of the penetrated sediments by the magnitude of the measured in-situ thermal conductivity value. Values above $\sim 1 \mathrm{Wm}^{-1} \mathrm{~K}^{-1}$ point to denser and more compacted sea floor sediments in comparison to soft, calcareous mud usually found in basins with moderate to high sedimentation rates. In addition, signs of wear on the rod (e.g. fresh scratches in the metal) and lack of mud adherence to the measuring rod point to compacted material. In fact, no adherence of mud was inadvertently observed in area 13. However, mud adherence to the rod was observed at all points in area 14, which led us to conclude - also in conjunction with the measured $\lambda$-values of $\sim 0.85 \mathrm{Wm}^{-1} \mathrm{~K}^{-1}$ in area 14 - that soft sediments were encountered in latter area at all points of measurement. Direct evidence for compacted sea floor sediments is, in addition, obtainable by the reflection pattern obtained by acoustic sea floor surveys.

The markedly different degree of sediment compaction in areas 13 and 14 is also reflected by the standard deviations of the measured $\lambda$-values. Values for standard deviation in area 13 have a tendency to exceed those of area 14. The reason for this observation is not entirely clear. One might speculate that the thermal contact between the penetrating rod and the compacted sediment suffers the more the sediment is compacted, or that uneven sediment compaction plays a role.

The in-situ measurement of $\lambda$ at site HF25 with the sensor at $0.62 \mathrm{~m}$ depth below sea floor yielded an unrealistically low value of $0.47 \mathrm{Wm}^{-1} \mathrm{~K}^{-1}$. We have rejected this value in our final analysis (inclusion would give a mean $\lambda$-value of $0.83 \mathrm{Wm}^{-1} \mathrm{~K}^{-1}$ with a standard deviation of $0.2 \mathrm{Wm}^{-1} \mathrm{~K}^{-1}$ ). Figure 2 shows a compendium of all accepted in-situ $\lambda$-values (excluding one rejected value from site HF25 - see above), which clearly demonstrate the different sediment character in areas 13 and 14. With exception of HF17, all sited show an increase in $\lambda$ with depth. We encountered at site HF17 particularly hard ground at the sea bottom (slight buckling of rod) and suspect that here a rather hard sediment layer at top of the sea sediments was penetrated.

The measured temperatures within the sediments increased (with the exceptions of one temperature outlier each in HF17 and HF29 - see Fig. 3) in linear behavior with depth, and $T$-gradients were derived with good accuracy. The results of our heat flow measurements are given in Table 1.

\section{Water column temperatures}

Each time the heat flow probe descended through the water column, the temperature distribution was automatically

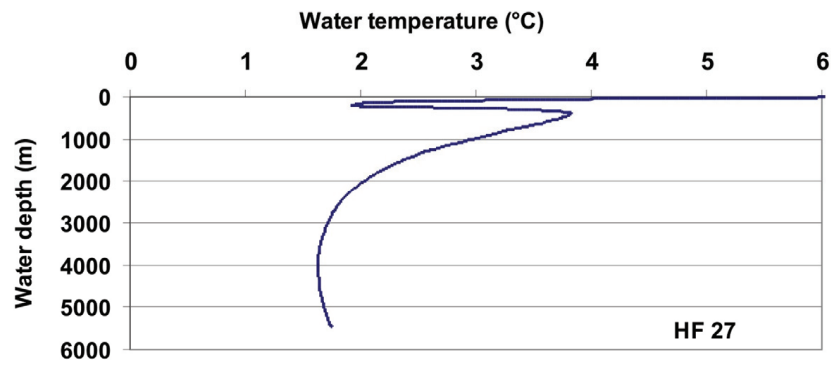

Fig. 4. An atypical increase of seawater temperatures - shown here for HF27 - was observed at three sites below $\sim 3800 \mathrm{~m}$, whose cause is unknown. The observed temperature inversion is not believed to adversely affect the heat flow measurements.

recorded by all temperature sensors. Water temperatures normally decrease monotonously to the sea floor below the layer of warm surface waters. Three recordings in the western sector of area 13, however, showed an unusual $T$-curve (see, e.g. $T$-curve at HF 27; Fig. 4). Here we noted a small but systematic temperature increase at depths $\geq 3800 \mathrm{~m}$, which is equivalent to a position of about $1000-1500 \mathrm{~m}$ above the sea floor. The depth of recorded temperatures was estimated from the average descend velocity $\left(\sim 1 \mathrm{~m} \mathrm{~s}^{-1}\right)$ of the probe through the water column. Typical $T$-depth curves were measured at the other 4 stations in excellent agreement with CTD-measurements performed during the cruise (Dullo and Baranov, 2009). Therefore, we exclude the possibility of an instrumental error.

It appears that either very cool water (probably from the north) penetrated the water column at a depth of approximately $3800 \mathrm{~m}$ or, alternatively, we encountered a regional flow system that draws warm bottom waters from shallow $(\leq 3800 \mathrm{~m})$ into deeper positions. The latter process would, however, require a sufficiently high density (increased salinity?) of the down-drawn waters to maintain a stable stratification of the whole water body.

The quality of the heat flow measurements should not be impeded by this temperature inversion in the water column if it represents a permanent feature. Alternatively, in the case of a short term phenomenon, any surface heating of the sea floor would result in a reduction of the measurable heat flow in the top sediments. In that case, the true heat flow values at the affected sites would have to be even revised upwards by values that depend on the timing of the near surface heating.

\section{Discussion - interpretation}

Area 13 is characterized by a horst and graben structure. Therefore, a terrain correction should be applied to all points of measurement with the exception of point HF29, which is located on a broad and evenly inclined slope on the northwest side of the Meiji Seamount. A first order approximation of the required terrain correction to the heat flow values 
is derived from a numerical model (Delisle and Berner, 2002) that mimics the terrain geometry at sites HF17, HF25, and HF27. A regional background value for heat flow of $60 \mathrm{~m} \mathrm{Wm}^{-2}$ was assumed in correspondence with the age of the oceanic crust. HF17 and HF27 were both positioned at the edges of steep slopes. Based on the modeled terrain correction, the heat flow value of HF17 should be corrected by $-15 \mathrm{~m} \mathrm{Wm}^{-2}$, HF25 by a negligible value of $+1 \mathrm{~m} \mathrm{Wm}^{-2}$, and $\mathrm{HF} 27$ by $-13 \mathrm{~m} \mathrm{Wm}^{-2}$. In conclusion, these terrain corrections do not explain the observed anomalously high heat flow values.

According to Parsons and Sclater (1977), heat flow values in oceanic crust of Cretaceous age should average today around $50-60 \mathrm{~m} \mathrm{Wm}^{-2}$. However, we observed in area 13 inadvertently high heat flow between $100-280 \mathrm{~m} \mathrm{Wm}^{-2}$, indicating either a heat source within the crust or the occurrence of a highly disturbed temperature field caused by fluid flow or erosion. The possible existence of a mantle plume (see above) favors in principle the notion of a buried magma chamber below the observed points of high heat flow. Theoretically, a magmatic source would have to be buried about $\geq 15 \mathrm{~km}$ depth below sea floor to cause a heat flow anomaly of $\geq 100 \mathrm{~m} \mathrm{Wm}^{-2}$ by pure heat conduction. Since such bodies usually initiate vigorous convective fluid flow, in particular above their roof section, the assumption of convectively heated rock volumes in a shallower position would be more appropriate. Fluid flow should be concentrated along fracture zones, with the implication of a concentration of high heat flow areas, where fracture zones intersect the sea floor. Figure 5 shows positions and measured values of all heat flow stations in area 13 together with the bathymetry. Two points with high heat flow appear to reside near major fractures; however, they are not the site where the highest heat flow value was found.

No conclusive evidence other than elevated heat flow points to the presence of a shallow plutonic body below the western flank of Meiji Seamount. Negative indications such as above discussed $C C^{\prime}$-profile by Levin et al. (2002) argue against it. Therefore, considering the old age of the oceanic crust, a magmatic heat source in the area is thought unlikely to cause the observed heat flow anomaly.

It is well known that natural convection in fractured media - a common feature in cooled oceanic crust - can cause local heat flow anomalies. Alternatively, high heat flow might also be due to rapid erosion, whereby warm and formerly deep-seated rocks are brought to near the sea floor, thereby mimicking an elevated heat flow.

\subsection{Natural convection}

The magnitude of a positive heat flow anomaly caused by rising fluids in the crust depends critically on two factors: the depth extent over which the fluid rises; and secondly, the speed of ascend. Bredehoeft and Papadopoulos (1965) have presented an analytical equation by which the increase

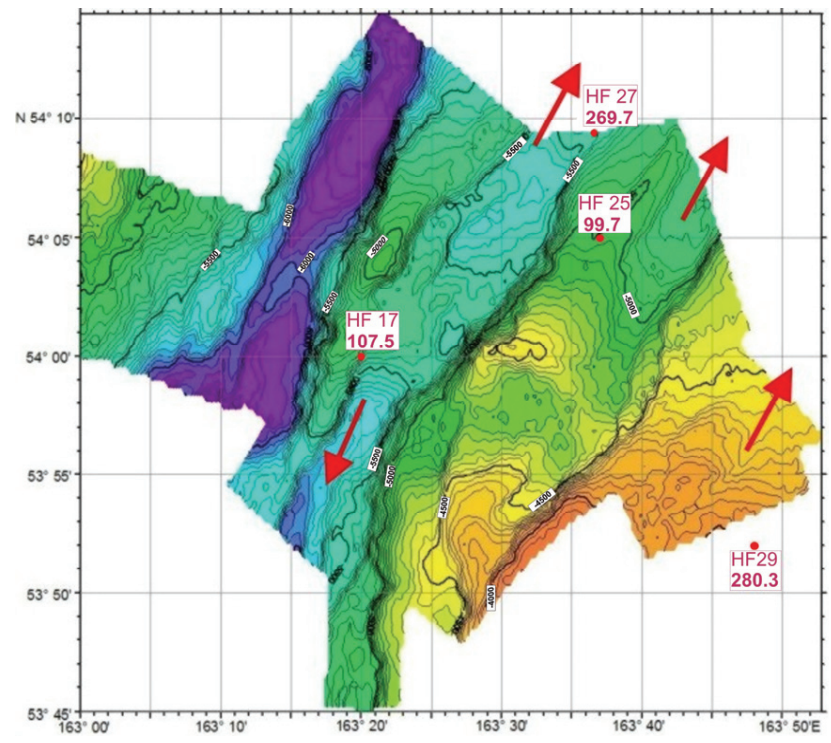

Fig. 5. Area 13: shown is the bathymetry, major erosion channels (red arrows) cut into the western flank of Meiji Seamount, which presently descends toward the subduction trench (violet color) offshore Kamchatka. Positions of heat flow stations and heat flow values in $\mathrm{m} \mathrm{Wm}^{-2}$, measured during cruise SO201-2, are indicated in red. Bathymetry is based on data collected during SO201-2 by $\mathrm{R} / \mathrm{V}$ Sonne. The high heat flow values in old oceanic crust are believed to be caused by deep seated natural convection in a tectonically stressed and newly fractured medium. Map was provided by B. Baranov (personal communication, 2009).

in heat flow as function of both of these factors can be evaluated. Figure 6 presents a graphical illustration of this relation. Given a deep seated background heat flow value of $60 \mathrm{~m} \mathrm{Wm}^{-2}$, a vertical flow rate of $1.5 \mathrm{~cm} \mathrm{a}^{-1}$ (depth extent of circulation $=4 \mathrm{~km}$ ) or $\sim 6 \mathrm{~cm} \mathrm{a}^{-1}$ (depth extent of circulation $=1 \mathrm{~km}$ ) are required to cause a heat flow anomaly on the order of about $300 \mathrm{~m} \mathrm{Wm}^{-2}$.

The approach by Bredehoeft and Papadopoulos (1965) pertains to a homogeneous medium of constant permeability. The crustal segment under area 13 is clearly fractured. Any fractured medium can be considered to possess an average permeability, if one integrates over a rock volume with dimensions in excess of the given fracture spacing, which in the case of old oceanic crust can be found within the range of ten to several tens of meters. The above analysis is applied with this image in mind.

All available geothermal data from the region seem to indicate a large area affected by high heat flow with values between $100-280 \mathrm{~m} \mathrm{Wm}^{-2}$, though we cannot exclude the possibility that the area is made up of several smaller sized anomalies primarily bound to fracture systems. Assuming ("extreme case") that we are dealing with only one anomaly and integrating over this area, the annually required water volume involved in the convection to cause this regional heat flow anomaly is on the order of $\sim 90-340 \times 10^{6} \mathrm{~m}^{3}(60 \times 30$ 


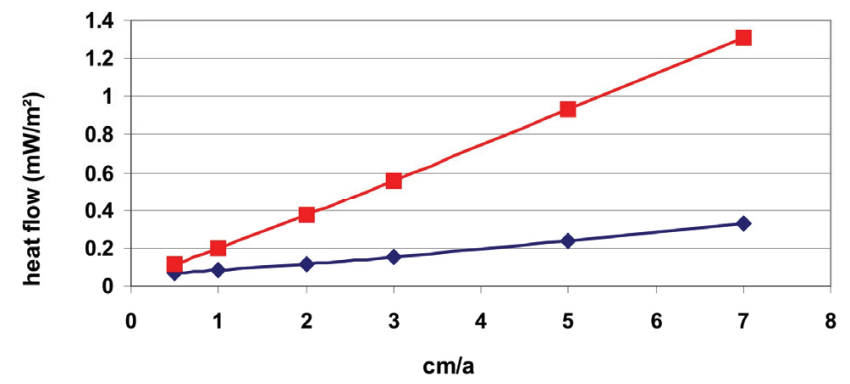

Fig. 6. Shown is the increase of heat flow (deep-seated background heat flow $=60 \mathrm{~m} \mathrm{Wm}^{-2}$ ) as function of ascend rate of fluids over a depth interval of $1000 \mathrm{~m}$ (blue) or $4000 \mathrm{~m}$ (red) according to an analytical solution provided by Bredehoeft and Papadopoulos (1965).

nautical miles $x$ ascend velocity). This large number begs the question, if we observe only internal convection or if cool bottom waters are drawn into the oceanic crust to participate in the convection process. Both flanks of the seamount chain would provide easy access for fluids to enter deeper crustal portions; a negative thermal anomaly at the entry points would be the consequence. When we accept a value of $60 \mathrm{~mW} \mathrm{~m}^{-2}$ as regional background for the oceanic crust of Cretaceous age, then only a limited area east of the subduction trench can be identified, which, via observed low heat flow, might qualify as a potential region for inflow of bottom waters into the oceanic crust. It is proposed that the most plausible process leading to the observed heat flow anomaly is internal convection within the fractured rock masses that redistributes heat from depth to near the rock surface. Bending of the subducting oceanic plate is believed to be associated with deep reaching fracturing of the rock masses (Grevemeyer et al., 2005), which is inductive to bring fracture fluids in contact with hot rocks at depth. Hot fluids are then forced via buoyancy forces to near the sea floor. As the fluids cool off they are drawn back - presumably along the lateral limits of the anomaly - to depth for reheating. They might mix during descend with cooler fluids from the outside. It is, however, a question of the relative quantities of cold and warm fluids involved in the mixing, which determines if an accompanying negative heat flow anomaly near the seafloor will evolve or not. In our case, the lack of evidence for such an anomaly favors the model of a largely self-contained system of natural convection as the most likely cause for the observed elevated heat flow.

\subsection{Erosion}

Continuous erosion or episodic slumping of material will inadvertently bring deeper (and warmer) material closer to the surface. Figure 7 presents a theoretical analysis of the relation between erosion rate and heat flow observable at the erosion surface. This model starts with an initial heat flow of $60 \mathrm{~m} \mathrm{Wm}^{-2}$ and the follow-

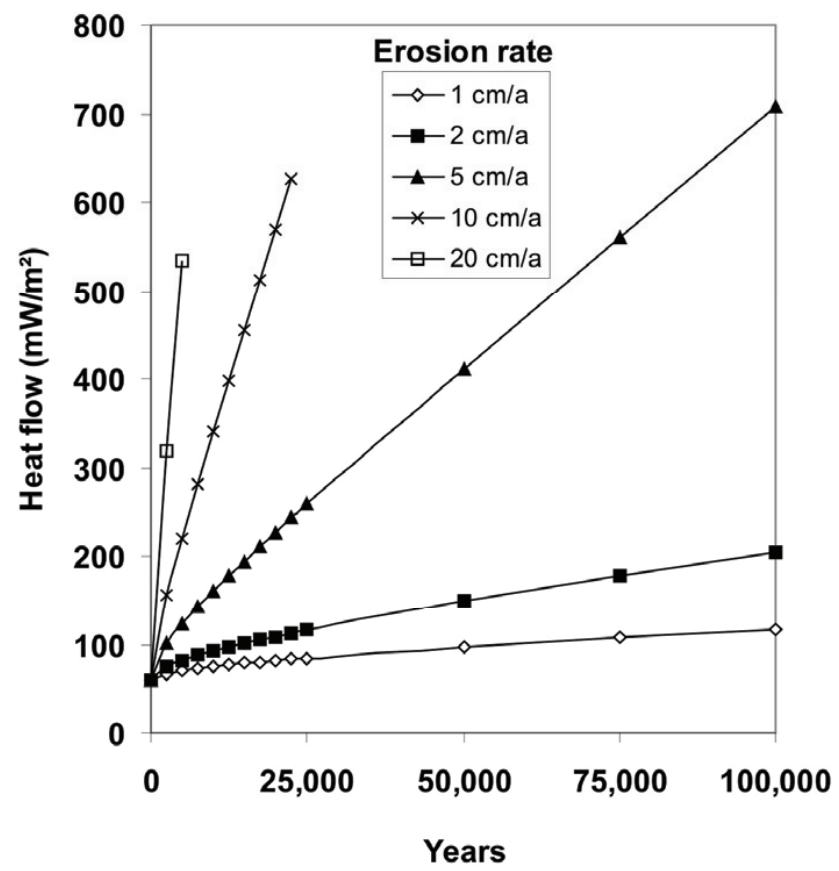

Fig. 7. Increase of heat flow as function of erosion rate and time. Steady erosion lifts deeper-seated and warmer sediments closer to the sea floor, with the consequence of artificially enhanced heat flow. The shown relation is based on an analytical solution of this situation, initially presented by Benfield (1949).

ing rock parameters: $\lambda=1.7 \mathrm{Wm}^{-1} \mathrm{~K}^{-1}$ (assumed average value for the whole rock column); and thermal diffusivity $a=0.77 \times 10^{-6} \mathrm{~m}^{2} \mathrm{~s}^{-1}$. The analytical equation to solve for the subsurface temperature field (from which the surficial heat flow value can be deducted), given the case of constant erosion, was initially developed by Benfield (1949) - see also Kappelmeyer and Hänel (1974).

According to this model, high heat flow values on the order of $280 \mathrm{~m} \mathrm{Wm}^{-2}$ can be caused by an erosion rate of $5 \mathrm{~cm} \mathrm{a}^{-1}$ within $25000 \mathrm{yr}\left(10 \mathrm{~cm} \mathrm{a}^{-1}\right.$ within $\left.7500 \mathrm{yr}\right)$, which is equivalent to a mass loss of a $1250 \mathrm{~m}(750 \mathrm{~m})$ high rock column. The shown relation implies that one fairly recent major slump is capable of causing a temporary high heat flow situation on the erosion scarp. These erosion rates should be used as "average values" over a timescale of decades, since it appears to be more realistic to assume a scenario of distinct slide events over time.

Each single slide event will expose warmer material to the sea floor and induce higher heat flow instantly, which will decay exponentially to lower values until the next slide occurs.

The topography of investigated area 13 (see Fig. 4) shows various signs of recent erosion. Tectonic forces acting on the descending oceanic crust cause strong segmentation, resulting in a horst and graben structure. Erosion channels (red arrows in Fig. 5) develop primarily in the graben sections. 

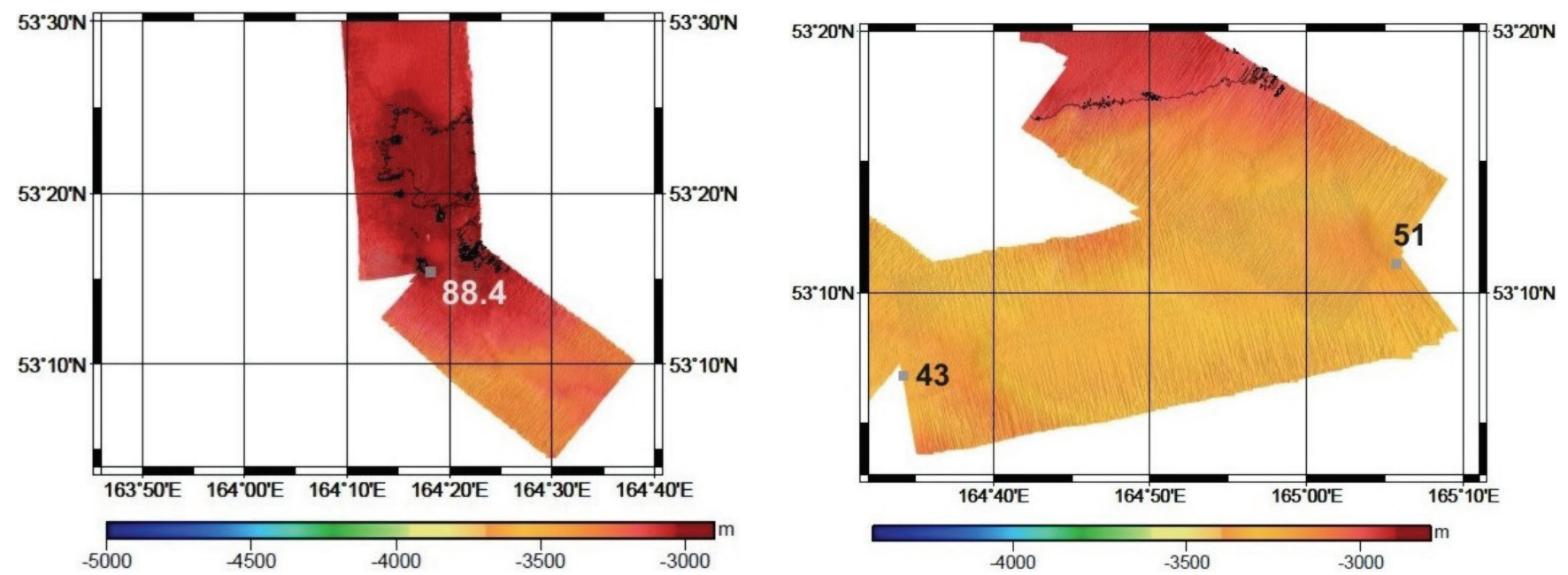

Fig. 8. Area 14: bathymetry and position of heat flow stations and heat flow values in $\mathrm{m} \mathrm{Wm}^{-2}$ as measured during cruise SO201-2 (values in white or black). This terrain is flat in comparison to area 13, its subsurface presumably tectonically less disturbed. Regional heat flow is lower than in area 13, indicating absence of natural convection in the subsurface. Map was provided by B. Baranov (personal communication, 2009).

HF25, located near a ridge, seems to have experienced the least erosion in comparison. HF17 and HF27 both rest on the side of a graben, which slopes from a vertex near HF17 to the south and north at angles in excess of $3.5^{\circ}$. A particularly well developed erosion channel exists at the southern extension. Deep erosion is implied by the erosion channel directly to the east of position HF25 with probably a similar amount of mass loss having occurred on the other side of the ridge to the west (position HF27). Little can be said with reference to HF29 on a position outside of the available detailed bathymetry. Recent slumping might have occurred in this area down the slope to the north, which appears to feature a current slope angle of about $4^{\circ}$.

The short time spans and high rates of erosion required to result in the observed high heat flow appear to be implausible. On the other side, recent erosion events might have contributed, to some extent, to the observed elevated heat flow at some sites.

The situation in area 14 appears to fully support the above analysis. Figure 8 shows the bathymetry around stations Hf34, HF36 and HF38. HF34 is sited on a slope and is the only station in area 14 that shows elevated heat flow. Stations HF36, and HF38 were both sited on flat terrain. Both show low heat flow, which is in close agreement with the theoretical heat flow value for oceanic crust of Cretaceous age (see, e.g. Parsons and Sclater, 1977).

All available heat flow anomalies from the area south of the Kurile-Kamchatka island arc system and east of Kamchatka are plotted in Fig. 9. Heat flow measurements around the Meiji Seamount show, with the exception of this fragmented northwestern to southwestern flank, the expected range of values around $50-60 \mathrm{~m} \mathrm{Wm}^{-2}$ for oceanic crust of

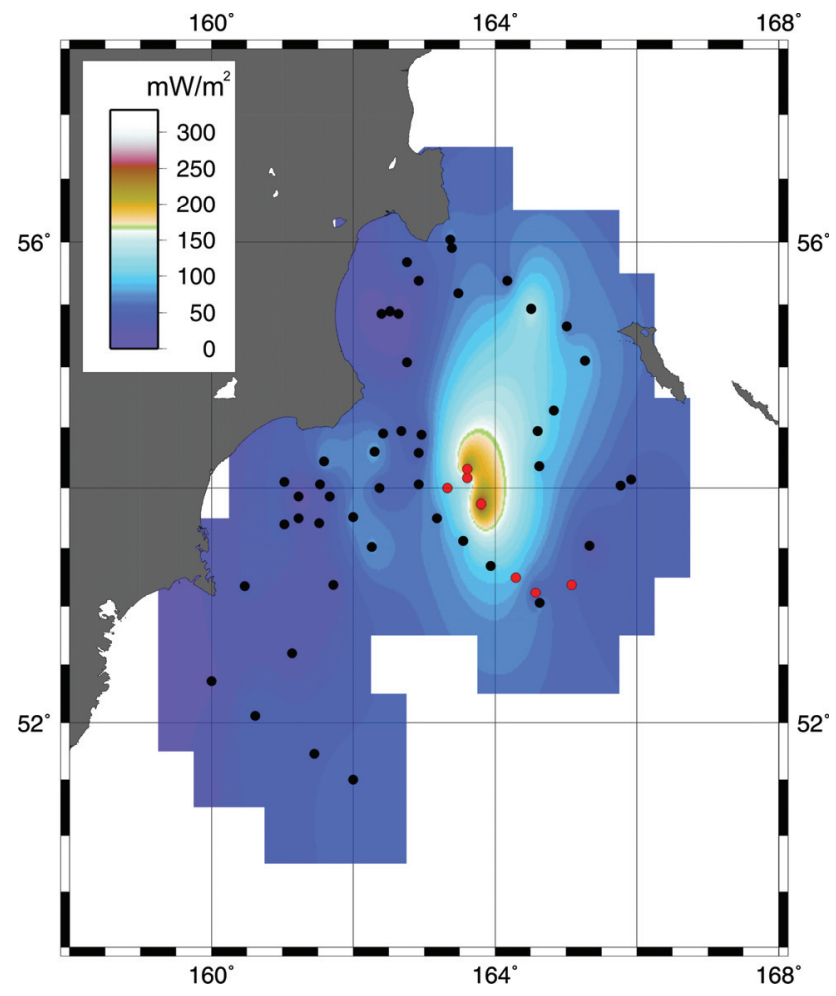

Fig. 9. Summary of all available heat flow values for the area east of Kamchatka and south of the Kurile-Kamchatka island arc system. Data are compiled from measurements during cruise SO201-2 and values provided by Smirnov and Sugrobov (1982) and Smirnov et al. (1991). 
Cretaceous age. High heat flow is also observed near the transform fault associated with at the northern edge of the down-going Pacific Plate. Both positive heat flow anomalies might be connected. This connection cannot be definitively determined due to lack of heat flow data between this transform fault and the flank region of the Meiji Seamount.

\section{Conclusions}

Our heat flow measurements during the KALMARexpedition have augmented earlier data previously published by Russian workers and summarized in Tuezov et al. (1991). Both data sets fit well together and re-emphasize the already earlier identified presence of elevated heat flow along the western flank of the Meiji Seamount. The heat flow anomaly coincides with the crust descending toward the subduction zone at the position where it suffers strong fragmentation into a horst and graben structure. Bathymetric data (Fig. 5) suggest numerous erosion channels that have cut into the downthrown blocks of the fragmented crust. Strong erosion occurs as well along the flanks of the horst structures.

In contrast to earlier speculation about a deep heated heat source as the cause of this anomaly - for which there is no hard independent geophysical evidence available - we favor an alternative interpretation, which associates elevated heat flow primarily with natural convection within the highly fractured oceanic crust. Recent slumping along the flanks of the seamount chain, thereby uncovering formerly deeper seated, warmer parts of the crust, might locally enhance heat flow.

Acknowledgements. We gratefully acknowledge financial assistance by the BMBF and the Russian Foundation of Basic Researches and the Russian Academy of Sciences. We would like to thank Captain Meyer and his crew of R/V Sonne for the professional support of our research project during cruise SO-201-2. I would like to thank the two reviewers for their valuable input.

Edited by: J. C. Afonso

\section{References}

Benfield, A. E.: The effect of uplift and denudation on underground temperatures, J. Appl. Phys., 20, 66-70, 1949.

Bredehoeft, J. D. and Papadopoulos, I. S.: Rates of vertical groundwater movement estimated from the Earth's thermal profile, Water Resour. Res., 10(2), 325-329, 1965.

Creager, J. S., Scholl, D. W., Boyce, R. E., Echols, R. J., Fullam, T. J., Grow, J. A., Koizumi, I., Lee, H. J., Ling, H. Y., Stewart, R. J., Supko, P. R., and Worsley, T. R.: Initial Reports of the Deep Sea Drilling Project, vol. 19, US Gov. Print. Off., Washington, DC, 913 pp., 1973.
Davaille, A. and Lees, J. M.: Thermal modelling of subducted plates: tear and hotspot at the Kamchatka corner, Earth Planet. Sc. Lett., 226, 293-304, 2004.

Delisle, G. and Berner, U.: Gas hydrates acting as cap rock to fluid discharge in the Makran accretionary prism?, in: The tectonic and climatic evolution of the Arabian Sea region, edited by: Clift, P. D., Kroon, D., Gaedicke, C., and Craig, J., Geol. Soc., London, Special Publications, 195, 137-146, 2002.

Delisle, G. and Zeibig, M.: Marine heat flow measurements in hard ground offshore Sumatra, EOS, 88(4), 38-39, 2007.

Dullo, C. and Baranov, B.: KALMAR: Kurile-Kamchatka and Aleutian marginal sea-island arc-systems: geodynamic and climate interaction in space and time, Cruise Report SO201-2, IFMGeomar, Kiel, 139 pp., 2009.

Gorbatov, A., Kostoglodov, V., Suárez, G., and Gordeev, E.: Seismicity and structure of the Kamchatka subduction zone, J. Geophys. Res., 102(B8), 17883-17898, 1997.

Gorbatov, A., Fukao, Y., Widiyantoro, A., and Gordeev, E.: Seismic evidence for a mantle plume ocean wards of the KamchatkaAleutian trench junction, Geophs. J. Int., 146, 282-288, 2001.

Grevemeyer, I., Kaul, N., Diat-Naveas, J. L., Villinger, H. W., Ranero, C. R., Reichert, C.: Heat flow and bending-related faulting at subduction trenches: case studies of Nicaragua and Central Chile, Earth Planet. Sc. Lett., 236, 238-248, 2005.

Kappelmeyer, O. and Hänel, R.: Geothermics, with special reference to application, Gebr. Bornträger, Berlin, 238 pp., 1974.

Levin, V., Shapiro, N., Park, J., and Ritzwoller, M.: Seismic evidence for catastrophic slab loss beneath Kamchatka, Nature, 418, 763-767, 2002.

Parsons, B. and Sclater, J. G.: An analysis of the variation of ocean floor bathymetry and heat flow with age, J. Geophys. Res., 82(5), 803-827, 1977.

Smirnov, Y. B. and Sugrobov, V. M.: Terrestrial heat flow in the Kurile-Kamchatka \& Aleutian provinces - I Heat flow and tectonics, Volcanol. Seismol., 1, 59-73, 1979.

Smirnov, Y. B. and Sugrobov, V. M.: Terrestrial heat flow in the Kurile-Kamchatka \& Aleutian provinces - II The map of measured and background heat flow, Volcanol. Seismol., 1, 16-31, 1980.

Smirnov, Y. B. and Sugrobov, V. M.: Terrestrial heat flow in the northwestern Pacific, Tectonophysics, 83(1-2), 109-122, 1982.

Smirnov, Y. B., Sugrobov, V. M., and Yanovsky, F. A.: Terrestrial heat flow of Kamchatka, Volcanol. Seismol., 2, 41-65, 1991.

Sugrobov, V. M. and Yanovsky, F. A.: Terrestrial heat flow, estimation of deep temperature and seismicity of the Kamchatka region, Tectonophysics, 217(1-2), 43-53, 1993.

Tuezov, I. K., Epaneshnikov, V. D., and Gornov, P. Y. U.: Heat field of the lithosphere in northeast Asia and the northwestern sector of the Asia-Pacific transition zone, in: Terrestrial heat flow and the lithosphere structure, edited by: Cermak, V. and Rybach, L., Springer-Verlag, Berlin, 238-263, 1991.

Yogodzinski, G. M., Lees, J. M., Churikova, T. G., Dorendorf, F., Wörner, G., and Volynets, O. N.: Geochemical evidence for the melting of subducting oceanic lithosphere at plate edges, Nature, 409, 500-504, 2001. 